\title{
Enhancement of clonal growth of normal human keratinocytes in a serum-free medium by Lithium ions, Dibutyrl-Cyclic AMP and Prostaglandin $\mathrm{E}_{1}$
}

\author{
John J Wille" and Jong Y Park ${ }^{2}$ \\ ${ }^{1}$ Department of Biochemistry, Sloan Kettering Division of Southern Research Institute, Birmingham, AL, USA \\ ${ }^{2}$ Department of Cancer Epidemiology, Moffitt Cancer Center, Tampa, FL 33612, USA
}

\begin{abstract}
A serum free medium (MCDB153) was designed to support the clonal growth of normal human keratinocytes (NHK) when supplemented with two protein growth factors, insulin-like growth factor-1 (IGF-1) and epidermal growth factor (EGF), We now report the results of new clonal growth studies showing enhanced clonal growth of NHK by three new non-protein growth factors. Newborn NHK cells were plated at $500 \mathrm{cells} / \mathrm{cm}^{2}$ in serum-free basal media supplemented singly with one the following additives: di-butyryl cyclic AMP (diBcAMP, $1 \times 10-4 \mathrm{M})$, lithium chloride $(10 \mathrm{mM})$, and prostaglandin E1 (10 ug/ml) in media supplemented with either IGF-1 only or IGF-1 plus EGF. All dishes were fixed ten days later stained with crystal violet stain (0.2\%) and photographed. DiBcAMP in combination with IGF-1 enhanced clonal growth relative to control dishes supplemented with IGF-1 plus EGF, indicating that diBcAMP can completely eliminate EGF as a necessary growth factor. Likewise single addition of lithium ions to SFM in combination with IGF-1 enhanced clonal growth relative to controls supplemented with IGF-1 plus EGF. Finally, PGE1 enhanced NHK clonal growth in dishes supplemented with either IGF-1 alone, with IGF-1 plus EGF and even with no protein growth supplementation relative to control dishes supplemented with IGF-1 plus EGF. PGE1 appears to eliminate the need for both EGF and IGF-1. A second study was undertaken to examine the enhancing effect of non-protein factors in the presence of elevated levels (3X) of six key amino acids (his, met, phe, tryt, ileu and tyr) that allow attainment of higher clonal cell densities. Elevated amino acids actually suppressed the enhancing effect of lithium ions on clonal growth. By contrast, elevated amino acids in SFM medium supplemented with PGE1 in combination with IGF-1 displayed enhanced clonal growth relative to control dishes supplemented with EGF plus IGF-1 in the elevated amino acid medium, suggesting a possible synergetic action of PGE1 and elevated amino acids. These results provide new insights in to the complex interplay between, non-protein ligands, nutritional factors and protein growth factor stimulation.
\end{abstract}

\section{Introduction}

The successful serum-free culture of normal epidermal keratinocytes was reported earlier [1-8]. Serum-free culture of NHK have a strict requirement for two protein factors, epidermal growth factor (EGF) and insulin (Ins) [9]. Insulin can be replaced with insulin-like growth factor-1 (IGF-1) [10,11]. Long-term culture of NHK often require further supplementation with bovine pituitary extracts (BPE), but can be avoided in early passage cultures. Elimination of either or both EGF and insulin/IGF-1 would be a significant advance as they are the most expensive ingredients in a defined SFM and are cost prohibitive for production of cultured epidermal autograft (CEA) production.

We have investigated the effect of several non-protein agents that appear to replace EGF and or insulin for the clonal growth of NHK. Among these are Lithium ions, dibutryl-cycluc adenosine monophosphate (diBcAMP), and prostaglandin $\mathrm{E}_{1}$ (PGE1). Previous studies have documented the need for many trace element metal ions in defined basal nutrient media and are included in many present day SFM compositions cited above. Here we report that Lithium ions stimulate the multiplication of human keratinocyte cells in a serumfree chemically defined medium. Lithium ions $\left(\mathrm{Li}^{+}\right)$can substitute for sodium ions in biological systems. It has a smaller atomic radius, it forms stronger ionic bonds. Lithium affects DNA and RNA synthesis and cell multiplication of mouse mammary gland explants cultured in a chemically-defined synthetic medium [12]. We also examined the effect of dibutryl-cyclic 3'-5'- cyclic adenosine monphosphate (dB-cAMP) on the clonal growth of normal human keratinocytes in a serum-free chemically defined culture medium either singly or in combination with Lithium ions. cAMP through cAMP-dependent PKA regulates actin organization and cell motility [13]. cAMP does not readily cross the plasma membrane of mammalian cells. Therefore, when one studies the action of cAMP on cells in culture the more membrane-soluble derivative, dibutryl-cyclic AMP (diBCAMP) is usually employed. An early study reported that diBCAMP inhibited epidermal cell division [14]. Addition of cholera toxin, a potent toxin, which induces an increase in intracellular cAMP, actually enhances keratinocyte growth [15]. Although, cholera toxin had no effect on human keratinocyte growth in a fetal serum-supplemented medium [1]. These disparate results may also reflect complex interactions and unpredictable consequences attributable to employing serumcontaining culture media. cAMP is a necessary growth factor for the clonal growth of uroethelial cells cultures in SFM [16].

Finally, we investigated the effect of prostaglandin $\mathrm{E}_{1}\left(\mathrm{PGE}_{1}\right)$ on

Correspondence to: John J. Wille, PhD., Bioplast, LLC, Department of Cell Biology, 9 Chesterfield Georgetown Rd., Chesterfield, NJ 08515, USA, Tel: 609261-1488; Fax: 609-291-1997; E-mail: jjwille@aol.com

Key words: Dibutry-3',5'-cyclic adenosine monophosphate, lithium ions, prostaglandin E1, serum-free media, non-protein growth factors, insulin-like growth factor-1, epidermal growth factors, normal human keratinocytes

Received: August 20, 2016; Accepted: September 05, 2016; Published: September 08, 2016 
NHK clonal growth. Little is known about it's effects on proliferation of epidermal keratinocytes. Human skin generates eicosanoids, which have been reported to regulate growth and differentiation of the epithelia but do not play a central role in inflammatory skin diseases [17]. $\mathrm{PGE}_{1}$ is a potent vasodilator and antithrombotic and injection of it have been widely used in circulatory disturbances in skin ulcers and various collagen diseases. PGE1 has shown clinical effectiveness for treatment of burn wounds [18]. PGE1 stimulates chloride secretion in a colonic epithelial cell line, which is associated with an increase in cyclic AMP level [19]. In addition, $\mathrm{PGE}_{1}$ is reported to increase EGF production in three-dimensional cultured human annulus cells [20]. A combination of ovine prolactin $(0.1 \mathrm{microgram} / \mathrm{ml})$ and $\mathrm{PGE}_{1}$ supports clonal growth of early passage human mammary epithelial cells in a serum-free chemically defined synthetic culture medium and has been included in selective media for keratinocytes and fibroblasts [4].

\section{Material and methods}

\section{Materials}

All chemicals were purchased from Sigma- Aldrich (St. Louis, MO). Cultures dishes were from Corning (Corning, NY). MCDB153 serumfree basal nutrient media were made fresh as previously described [11].

\section{Clonal growth assay/cell culture}

Methods for isolating and culturing primary and secondarypassage normal human neonatal normal human keratinocyte (NHK cells) were those previously employed [9]. Clonal growth assays were performed as previously described [9]. Secondary serially-passage cultures were seeded in duplicate sterile disposable $35 \mathrm{~mm}^{2}$ Petri dishes at $500 \mathrm{cells} / \mathrm{cm}^{2}$ in a MCDB153 SFM basal media and supplemented singly with the following additives: $\operatorname{diBCAMP}\left(1 \times 10^{-4} \mathrm{M}\right), \mathrm{LiCl}(10$ $\mathrm{mM})$, and PGE1 $(10 \mu \mathrm{g} / \mathrm{ml})$ with or without further supplementation with either or both insulin-like growth factor (IGF-1, $5 \mathrm{ng} / \mathrm{mL}$ ) and epidermal growth factor (EGF, 5-10 ng/mL). All dishes were fixed ten days later stained with crystal violet stain $(0.2 \%)$ and photographed for later analysis.

\section{Results}

\section{Growth stimulation of NHK by single addition of DiBcAMP} and $\mathrm{Li} \mathrm{Cl}$

Figure 1 presents photographs showing four different clonal growth assay dishes (A-D). The effect of single addition of diBcAMP (C) or Lithium Chloride (D) to SFM supplemented only with IGF-1 and fixed and stained after day 10 of clonal growth compared with SFM supplemented with both EGF and IGF-1 and fixed and stained after day 1 (A) and after day 10 (B) of clonal growth. The results show that both $\mathrm{dBcAMP}$ and Lithium Chloride not only have EGF-like activity as they replace EGF but actually enhance clonal growth relative to the combination of EGF plus IGF-1. One important implication of these results is the potential benefit of replacing expensive EGF with Lithium Chloride or diBcAMP as low cost non-protein growth factors.

\section{Enhancement of clonal growth of NHK by single addition of Prostaglandin E1}

Figure 2 presents photographs showing 5 different clonal growth assay dishes. There is only negligible clonal growth after just 1 day of growth (A) and much greater clonal growth 10 days later (D) in control SFM dishes supplemented with EGF plus IGF-1 as expected. Addition of $\mathrm{PGE}_{1}$ to SFM dishes already supplement with EGF and IGF-1 (B)

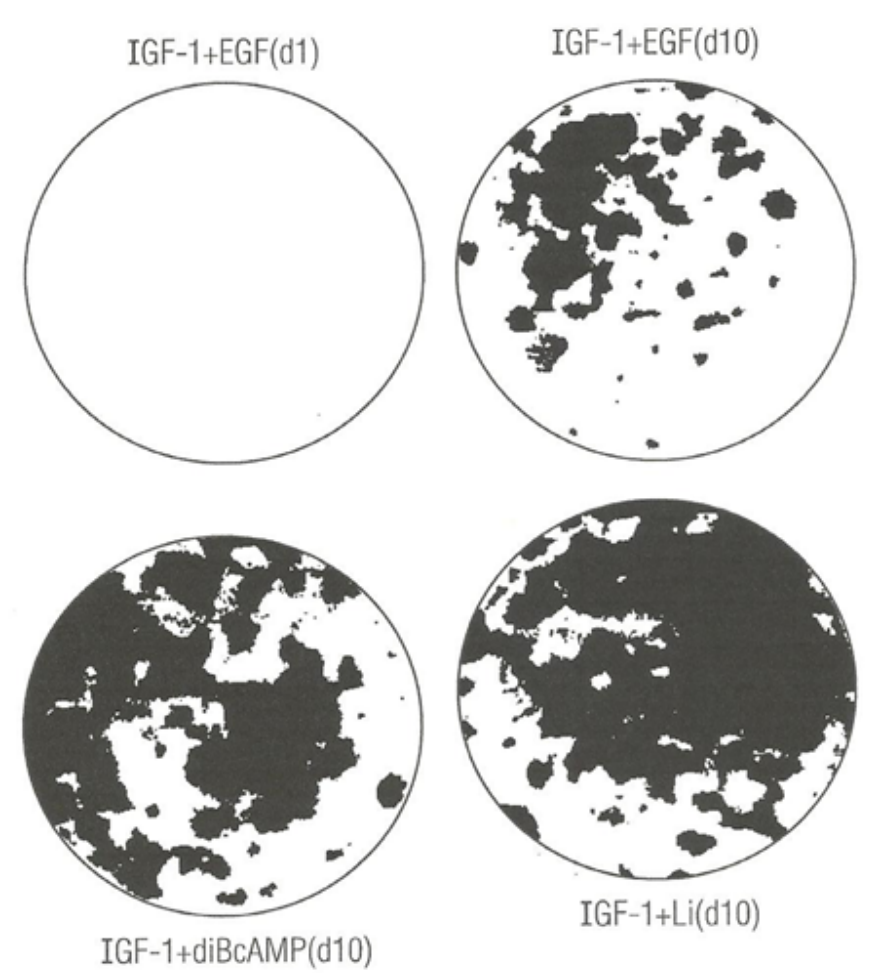

Figure 1. Photographs showing the enhancing effect of diButryl cyclic adenosine monophosphate (diBcAMP) and Lithium ions $\left(\mathrm{Li}^{+}\right)$on clonal growth of normal human keratinocytes. A) Control clonal growth assay dishes: (top left), labeled IGF-1+EGF, d1 (day one) and (top right), labeled IGF-1 + EGF, d10 (day ten). B) Experimental clonal growth assay dishes: culture medium containing IGF-1 $(5 \mathrm{ng} / \mathrm{mL})$ supplemented with diBcAMP $(0.1 \mathrm{mM})$ (bottom left), labeled IGF-1 + diBcAMP; C) culture medium supplemented with IGF-1 $(0.1 \mathrm{mM})$ and $\mathrm{Li}^{+}$ions (bottom right). All dishes were fixed with glutaraldehyde and stained with $0.2 \%$ crystal violet stain. The dishes were photographed (IX, magnification).

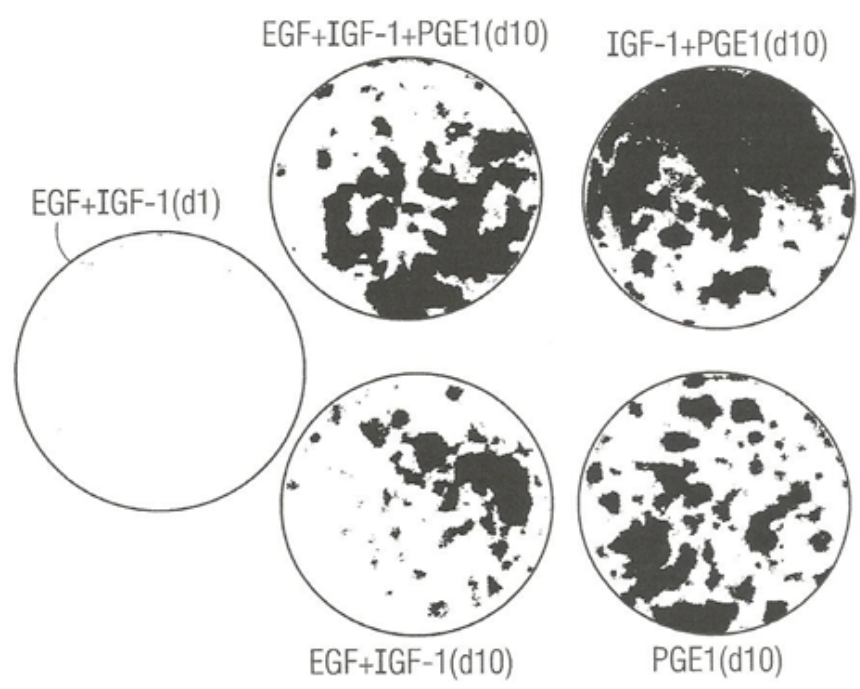

Figure 2. Photograph showing the enhancing effect of prostaglandin E1 (PGE1) in combination with IGF-1 or insulin (Ins) in the presence or absence of epidermal growth factor (EGF) on the clonal growth of normal human keratincytes. A) Control culture dishes: (top left), labeled EGF + IGF-1, (d1, day one); (middle bottom), labeled EGF + IGF -1 (d10, day 10). B) Experimental culture dishes: (top middle), labeled EGF + IGF-1 + PGE1, d10 (day ten); (top right), labeled IGF-1 + PGE1 (d10); bottom right- labeled PGE1 (d 10). All dishes were fixed with 5\% glutaraldehyde and stained with $0.2 \%$ Crystal Violet stain and. The dishes were photographed (IX, magnification).

and fixed and stained 10 days later exhibited enhanced clonal growth relative to control dish (D). Experimental dish (C) was supplemented 
with PGE1 and IGF-1 and no EGF. It greatly enhanced clonal growth relative to the control dish (D), indicating that PGE1 can replace EGF as a necessary growth factor, and exhibited greater clonal growth than mere addition of PGE1 to SFM already supplemented with EGF and IGF-1. Finally, we tested the effect of single addition of PGE1 to SFM without any protein growth factors (E). It exhibited clonal growth equal to PGE1 in combination with EGF and IGF-1, suggesting that the entire enhancement of PGE1 in combination with both EGF and IGF-1 may be due to PGE1 alone.

\section{Effect of elevated levels of key amino acid on PGE1 and Li ${ }^{+}$ ion - induced enhancement of clonal growth}

In an independent study, we examined the effect of elevated 6 key amino acids (his, ileu met, phe, tryt, and tyr) at three-times their normal concentration in MCDB153 basal nutrient medium on the effect of lithium chloride and PGE1. Figure 3 (right panel) shows that mere elevation of the six key amino acids (B) had a negative stimulatory effect on clonal growth of duplicate SFM dishes ( $(A, C)$ supplemented with Lithium Chloride and EGF and IGF-1 relative to duplicate control and Lithium Chloride dishes with the $1 \mathrm{X}$ level of amino acids (left panel). This may indicate that $\mathrm{Li}^{+}$ion is sequestered in medium containing high levels of amino acid.

By contrast, there was a significant enhancements of clonal growth in culture medium supplemented with PGE1 containing elevated levels of the six key amino acids (right panel) relative to the lower (1X) levels of amino acid when cultured in the presence of EGF and IGF-1 protein growth factors. This result indicates that the strength of the stimulatory effect of PGE1 is dependent on the nutritional action of elevated levels of amino acids.

\section{Discussion}

A cost-effective serum-free culture of human epidermal keratinocytes is of paramount importance for the in vitro formation of cloned human tissues by means of cell therapy, and eventually for the success of regenerative medicine's approach to replace diseased, injured, "worn-out/aged" and lost host tissue. This can be accomplished by eliminating either EGF or IGF-1 from a complete culture growth medium. Here, we have described three different non-protein growth promoting factors. Each is an additive that can be added to a chemically defined serum-free culture medium suitable for the growth and proliferation of rapidly growing normal human keratinocytes.

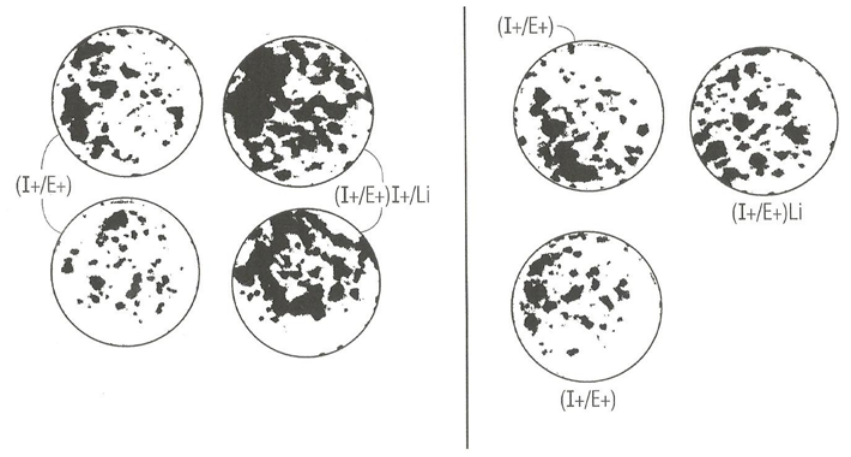

Figure 3. Photographs of clonal growth assay culture dishes showing the enhancing effect of PGE1 in combination with EGF and Insulin cultured in the presence of $1 \mathrm{X}$ level of amino acid (left panel) and in presence of $3 \mathrm{X}$ amino acids (right panel) on the clonal growth of normal human keratincytes. A) control culture dishes supplemented with $\mathrm{I}+/ \mathrm{E}+; \mathrm{b})$ experimental supplemented with $\mathrm{I}+/ \mathrm{E}+/ \mathrm{PGE} 1$. All dishes were fixed with $5 \%$ glutaraldehyde and stained with $0.2 \%$ Crystal Violet stain. The dishes were photographed (IX, magnification).
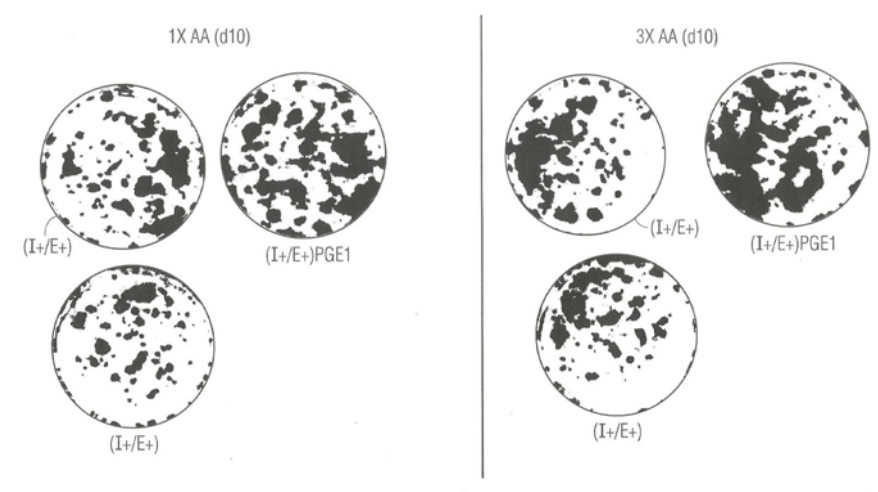

Figure 4. Photographs of clonal growth assay culture dishes showing the enhancing effect of Lithium ions $\left(\mathrm{Li}^{+}\right)$in combination with EGF and IGF-1 when cultured in the presence of $1 \mathrm{X}$ amino acid (left panel), and no enhancemernt when cultured in presence of $3 \mathrm{X}$ amino acids (right panel) on the clonal growth of normal human keratinocytes. A) control culture dishes supplemented with insulin $\left(\mathrm{I}^{+}\right)$and EGF $\left(\mathrm{E}^{+}\right)$only; B) experimental culture dishes supplemented with $\mathrm{I}^{+}$and $\mathrm{E}^{+}$plus PGE1. All dishes were fixed with $5 \%$ glutaraldehyde and stained with $0.2 \%$ Crystal Violet stain. The dishes were photographed (IX, magnification).

Lithium ions presented as a salt, lithium chloride, is readily soluble in the aqueous phase of the medium and can be added aseptically as a 1:100 fold dilution and as the terminal component from a $1 \mathrm{M} \mathrm{LiCl}$ concentrated stock solution to give a final concentration of $10 \mathrm{mM}$. Likewise, a $100 \mathrm{mM}$ stock solution of dibutryl-cAMP dissolved in alcohol can be diluted 1:1000 aseptically to yield a final concentration of $0.1 \mathrm{mM}$ and added as the terminal component to the final basal nutrient medium. Finally, $1 \mathrm{mg} / \mathrm{mL}$ stock solution of prostaglandin $\mathrm{E}_{1}$ can be diluted 1:1000 aseptically to yield a final concentration of $10 \mu \mathrm{g} /$ $\mathrm{mL}$ in the culture medium as the terminal component of the medium.

Lithiun ions qualify per se as an independent growth factor. The example of MCDB153 as a SFM is one of several SFM medium composition that could be improved by addition of one or more and combinations of the named non-protein growth factors to commercially available serum-free culture media designed for keratinocytes. Earlier work, reported that Lithium Carbonate stimulated the proliferation of keratinocytes in in vitro normal human skin explants [21]. The effect occurred in a media supplemented with $10 \%$ fetal calf serum raising doubts about confounding effects of serum, and the evidence for kerarinocyte proliferation was indirect microscope observations of cell crowding. In another tissue, the serum-free growth of human mammary epithelial cells is supported by addition of pituitary extracts [22]. Unfortunately, this addition defeats the purpose of having only defined growth promoting ingredients. Other non human cell studies have shown that Lithium can interfere with morphological movements and gene expression in the slime mold Dictyostelium discoideum [23], and embryological processes such as gastrulation in sea urchin [24], and amphibian embryos [25]. A possible mechanism by which Lithium ions interfere with cellular movements is by stabilizing cytoskeleton F-actin fibers [26,27]. More relevant to effects on cell growth is a report that $\mathrm{Li}^{+}$ions cause morphological alterations in various mammalian cell lines [28] at concentrations above $4 \mathrm{mM}$. The mechanism of action of Lithium ions is largely unknown but it can affect the intracellular phosphoinositide signaling pathway through depletion of the intermediate, inositol triphosphate (see Figure 5). In addition, when added to the culture medium of the ciliate, Blepharisma, it had an inhibitory effect on that cells photoresponses [29]. Lithium ions at $15 \mathrm{mM}$ when added to culture medium of the protozoan parasite, Herpetomonas, stimulated its growth [30]. 


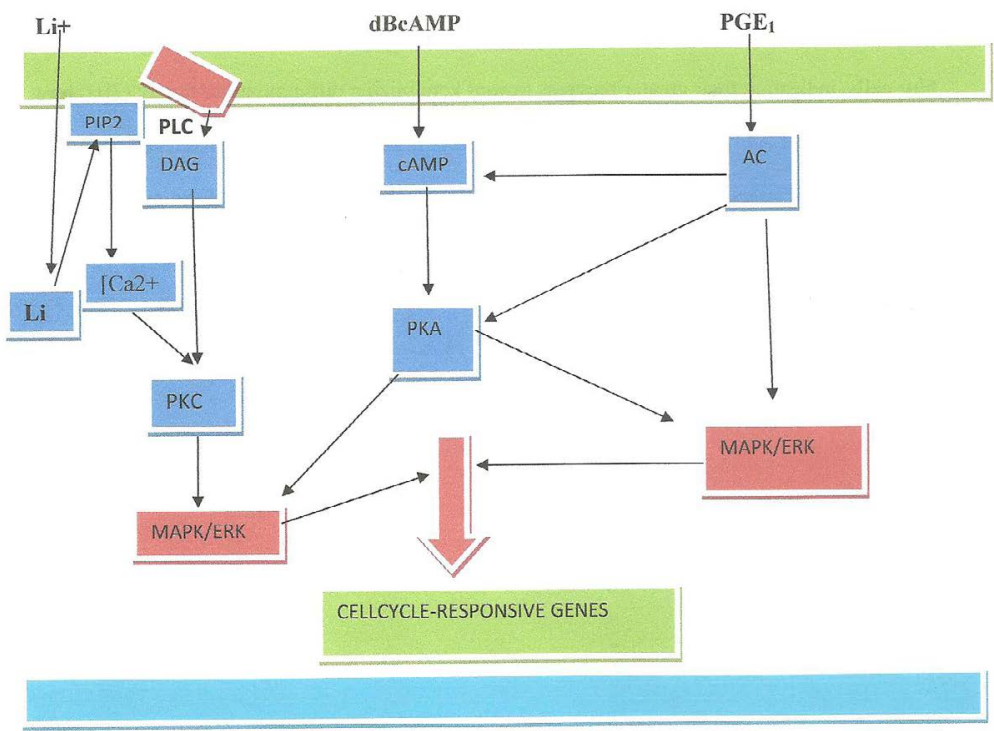

Figure 5. A hypothetical model of the mode of action of Lithium ions $\left(\mathrm{Li}^{+}\right)$, dibutryl 3' -5' cyclic adenosine monophosphate (dBcAMP), and prostaglandin E1 (PGE $\left.{ }_{1}\right)$ on activation of cell proliferation. Symbola: plasma-membrane phospholipase C, PLC,

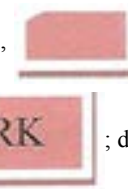

MAPK/ERK
; adenyl cyclase, $\mathrm{AC}$. diacylglycerol, DAG; phosphoinositol-diphosphate, $\mathrm{PIP}_{2}$ c calcium ion, [Ca2 $\left.{ }^{+}\right]$.
Lithium ions at $20 \mathrm{mM}$ concentration inhibited glucose synthesis in the rat liver [31]. Most relevant to the present report that Lithium ions at a concentration of $2-20 \mathrm{mM}$ had a stimulatory effect on insulin induced uptake of a-aminobutryic acid, synthesis of DNA and RNA and cell multiplication of mouse mammary gland explants cultured in a chemically-defined synthetic medium.

Cyclic AMP is synthesized from ATP by adenylcyclase, a plasma membrane enzyme, which is ordinarily activated by hormone ligand occupation of specific cell surface hormone receptors like the ligand, insulin. cAMP is an intracellular second messenger that is involved in a signaling cascade, which acts through a cAMP-dependent protein kinase (PKA) that phosphorylates nuclear DNA binding proteins, thereby turning on select DNA sequences for gene expression. cAMP also activates calcium channels, providing a minor pathway by which cAMP causes a release of growth hormone. In non-human systems, cAMP is a chemoattractant for slime mold cells. Like Lithium ions, cAMP through cAMP-dependent PKA regulates actin organization and cell motility [13].

We also report that $\mathrm{dBcAMP}$ enhances keratinocyte proliferation based on dramatic increase in number and size of colonies after 10 days of clonal growth. Earlier workers, found a modest increment in population doubling of less than 1 doubling in 7 days of batch culture growth in SFM [32]. Contrary to these findings, another author found that $\mathrm{dBcAMP}$ had no direct effect on keratinocyte proliferation [33]. Their 5-Brdur DNA synthesis detection method may have missed a minor stimulation in cell proliferation.

Previously, PGE1 and PGI and its analogues were shown to stimulate keratinocyte proliferation when treated with conditioned media containing cytokines released into the media by fibroblasts [34,35]. By contrast, we found that PGE1 directly stimulates serumfree clonal growth in the presence of IGF-1 and in the total absence of any added protein growth factor.
In summary, we propose (see Figure 5) a hypothetical model of the mode of action of Lithium ions, diBcAMP, and PGE1 as they impinge of the gene expression affecting the cell division cycle. We consider non-protein growth factors as first messengers or extracellular substances that include protein growth factors. As first messengers may not physically cross the phospholipid bilayer-cell membrane to initiate changes within the cell directly necessitating a second signal transduction mechanisms to transduce the first into second messengers, so that the extracellular signal may be propagated intracellularly and trigger proliferation. Second messengers triggered by Lithium ions are known parts of the phosphoinositide signalling pathway (A) which activates phosphoinositol kinase with the production of three second messengers, inositol triphosphate, diacylglycerol, and calcium. DBcAMP and PGE1 act by activating the cAMP second messenger pathway (B and $\mathrm{C}$ ). The cAMP second messenger signalling cascade involves downstream multi-cyclic kinases that link to mitogenactivated protein kinase (MAPK) and to transcription factors such as MYC that advance cell proliferation (see Figure 5 (A-C)).

\section{Acknowledgements}

This work was supported by a NIH-NCI Program Project Grant \# PO1-CA340968 to Biochemistry Department, Sloan-Kettering Division, Southern Research Institute, Birmingham, AL.

\section{References}

1. Peehl DM, Ham RG (1980) Growth and differentiation of human keratinocytes without a feeder layer or conditioned medium. In Vitro 16: 516-525. [Crossref]

2. Tsao MC, Walthall BJ, Ham RG (1982) Clonal growth of normal human epidermal keratinocytes in a defined medium. J Cell Physiol 110: 219-229. [Crossref]

3. Boyce ST, Ham RG (1983) Calcium-regulated differentiation of normal human epidermal keratinocytes in chemically defined clonal culture and serum-free serial culture. J Invest Dermatol 81: 33s-40s. [Crossref]

4. Ham R (1984) Methods for formulation of basal nutrient media. In: Methods in 
Molecular and Cell Biology. New York, pp 1-19.

5. Boyce ST, Ham RG (1984) Normal human keratinocytes.. In: In Vitro Model for Cancer Research. Eds. Webber M; Sekely L. CRC Press, Boca Raton, FL.

6. Nissley P, Adams S, Gaynes L, Anderson W, Nagarajan L, et al. (1985) Growth of cells in defined environments: The role of endogenous production of insulin-like growth factor. In: Proc Intl Symp Growth and Differentiation of Cells in Defined Environments. Springer-Verlag, Berlin. pp 332-343.

7. Ham RG (1984) Selective media. In: Cell Separation: Methods and Selected Applications. Vol. 3, Academic Press, Inc., pp 209-231.

8. Boisseau AM, Donatien P, Surlève-Bazeille JE, Amédée J, Harmand MF, et al. (1992) Production of epidermal sheets in a serum free culture system: a further appraisal of the role of extracellular calcium. J Dermatol Sci 3: 111-120. [Crossref]

9. Wille JJ, Pittelkow MR, Shipley GD, Scott RE (1984) Integrated control of growth and differentiation of normal human prokeratinocytes in serum-free medium: clonal analysis, growth kinetics and cell cycle studies. J Cell Physiol 121: 31-44. [Crossref]

10. Wille JJ Jr. US Patent No:, 5,686, 307. Serum-free medium for use in the formation of a histologically completeliving human skin substitute. issued Nov. 11, 1997.

11. Wille JJ, Burdge JJ, Park JY (2014) Methods for the preparation of an autologous serum-free cultured epidermis and for autografting applications. Methods $\mathrm{Mol}$ Biol 1195: 203-218. [Crossref]

12. Hori C, Oka T (1979) Induction by lithium ion of multiplication of mouse mammary epithelium in culture. Proc Natl Acad Sci U S A 76: 2823-2827. [Crossref]

13. Glenn HL (2003) Cyclooxygenase and cyclic AMP-dependent protein kinase regulate actin organization and cell motility. Electronic Doctoral Dissertations for U Mass Amherst. Paper AA1310490, January 1, 2003.

14. Voorhees JJ, Duell EA, Kelsey WH (1972) Dibutyryl cyclic AMP inhibition of epidermal cell division. Arch Dermatol 105: 384-386. [Crossref]

15. Green H (1978) Cyclic AMP in relation to proliferation of the epidermal cell: a new view. Cell 15: 801-811. [Crossref]

16. Wille JJ, Park J, Elgavish A (1991) Effects of growth factors, hormones, bacterial lipopoysaccharides, and lipotechoic acid on clonal growth of normal uretral epithelial cells in serum-free culture. J Cell Physiol 150: 52-58. [Crossref]

17. Ikai K (2000) Proinflammatory mediators of the arachidonic acid cascade. In: Biochemical Modulation of Skin Reactions. CRC Press, BocA Raton, FL. Pp 189- 201.

18. Gunji H, Ono I, Tateshita T, Kaneko F (1996) Clinical effectiveness of an ointment containing prostaglandin E1 for the treatment of burn wounds. Burns 22: 399-405. [Crossref]

19. Weymer A, Huott P, Liu W, McRoberts JA, Dharmsathaphorn K (1985) Chloride secretory mechanism induced by prostaglandin E1 in a colonic epithelial cell line. $J$ Clin Invest 76: 1828-1836. [Crossref]

20. Gruber HE, Hoelscher G, Loeffler B, Chow Y, Ingram JA, et al. (2009) Prostaglandin
E1 and misoprostol increase epidermal growth factor production in 3D-cultured human annulus cells. Spine J 9: 760-766. [Crossref]

21. Wolf R, D'Avino M, De Angelis F, Ruocco E, Lombardi ML (2000) Effects of lithium carbonate (Li2CO3) on in-vitro-cultured normal human skin explants. J Eur Acad Dermatol Venereol 14: 97-99. [Crossref]

22. Hammond SL, Ham RG, Stampfer MR (1984) Serum-free growth of human mammary epithelial cells: rapid clonal growth in defined medium and extended serial passage with pituitary extract. Proc Natl Acad Sci USA 81: 5435-5439. [Crossref]

23. Peters DJ, Van Lookeren Campagne MM, Van Haastert PJ, Spek W, Schaap P (1989) Lithium ions induce prestalk-associated gene expression and inhibit prespore gene expression in Dictyostelium discoideum. J Cell Sci 93: 205-210. [Crossref]

24. Nocente-McGrath C, McIsaac R, Ernst SG (1991) Altered cell fate in LiCl-treated sea urchin embryos. Dev Biol 147: 445-450. [Crossref]

25. Lazou A, Beis A (1993) Lithium induces changes in the plasma membrane protein pattern of early amphibian embryos. Biol Cell 77: 265-268. [Crossref]

26. Colombo R, Milzani A, Contini P, Dalle Donne I (1991) Effects of lithium ions on actin polymerization in the presence of magnesium ions. Biochem J 274: 421-425. [Crossref]

27. DalleDonne I, Milzani A, Fascio U, Ratti A, Colombo R (1993) Lithium preserves F-actin from the disarrangement induced by either DNase I or cytochalasin D. Biochem Cell Biol 71: 440-446. [Crossref]

28. Matthopoulos DP, Tzaphlidou M, Leontiou I (1995) Morphological alterations caused by lithium in various cell lines. Cell Biol Int 19: 499-506. [Crossref]

29. Libíková H, Pogády J, Wiedermann V, Breier S (1975) Search for herpetic antibodies in the cerebrospinal fluid in senile dementia and mental retardation. Acta Virol 19: 493495. [Crossref]

30. http://www.photobiology.com/photobiology99/contribution/ fabczak/index.htm.

31. Nakamura CV, Pinto AS (1989) Biological effects of lithium chloride on the insect trypanosomatid Herpetomonas samuelpessoai. Parasitology 99: 193-197.

32. Bosch F, Rodriguez-Gil JE, Hatzoglou M, Gomez-Foix AM, Hanson RW (1992) Lithium inhibits hepatic gluconeogenesis and phosphoenolpyruvate carboxykinase gene expression. J Biol Chem 267: 2888-2893. [Crossref]

33. Falanaga V (1991) Wounds 3: 73-.80

34. Zhou LJ, Ono I (2000) Stimulatory effects of dibutyryl cyclic adenosine monophosphate on cytokine production by keratinocytes and fibroblasts. Br J Dermatol 143: 506-512. [Crossref]

35. Zhang JZ, Maruyama K, Iwatsuki K, Ono I, Kaneko F (1994) Effects of prostaglandin E1 on human keratinocytes and dermal fibroblasts: a possible mechanism for the healing of skin ulcers. Exp Dermatol 3: 164-170. [Crossref]

36. Kaneko F, Zhang JZ, Maruyama K, Nihei Y, Ono I, et al. (1995) Prostaglandin I1 analogues, SM-10902 and SM-10906, affect human keratinocytes and fibroblasts in vitro in a manner similar to PGE1: therapeutic potential for wound healing. Arch Dermatol Res 287: 539-545. [Crossref]

Copyright: (C2016 Wille JJ. This is an open-access article distributed under the terms of the Creative Commons Attribution License, which permits unrestricted use, distribution, and reproduction in any medium, provided the original author and source are credited. 